\title{
An HSP90 cochaperone Ids2 maintains the stability of mitochondrial DNA and ATP synthase
}

\author{
Pei-Heng Jiang ${ }^{1}$, Chen-Yan Hou ${ }^{1}$ and Shu-Chun Teng ${ }^{1,2^{*}}$ (D)
}

\begin{abstract}
Background: Proteostasis unbalance and mitochondrial dysfunction are two hallmarks of aging. While the chaperone folds and activates its clients, it is the cochaperone that determines the specificity of the clients. Ids 2 is an HSP90's cochaperone controlling mitochondrial functions, but no in vivo clients of Ids2 have been reported yet.

Results: We performed a screen of the databases of HSP90 physical interactors, mitochondrial components, and mutants with respiratory defect, and identified Atp3, a subunit of the complex V ATP synthase, as a client of Ids2. Deletion of IDS2 destabilizes Atp3, and an a-helix at the middle region of Ids2 recruits Atp3 to the folding system. Shortage of Ids2 or Atp3 leads to the loss of mitochondrial DNA. The intermembrane space protease Yme1 is critical to maintaining the Atp3 protein level. Moreover, Ids 2 is highly induced when cells carry out oxidative respiration.
\end{abstract}

Conclusions: These findings discover a cochaperone essentially for maintaining the stability of mitochondrial DNA and the proteostasis of the electron transport chain — crosstalk between two hallmarks of aging.

Keywords: Aging, Proteostasis, Mitochondria, Ids2, ATP synthase

\section{Background}

Aging is a process with a decline of organismal function and an increase in the risk of disease and death. Mitochondrial dysfunction is one of the nine hallmarks of aging [1] that can be produced by aging-associated mitochondrial DNA (mtDNA) mutations [2], reduced mitochondriogenesis [3], destabilization of the electron transport chain [4] complexes $[4,5]$, altered mitochondrial dynamics, and defective quality control by mitophagy [6]. In aged cells, the efficacy of the respiratory chain tends to diminish, thus increasing electron leakage and reducing ATP generation [7].

Animal decomposes food to obtain ATP through oxidative reactions mainly in mitochondria, where carbohydrates, proteins, and fats undergo a series of metabolic reactions collectively called cellular respiration. Cellular

\footnotetext{
* Correspondence: shuchunteng@ntu.edu.tw

'Department of Microbiology, College of Medicine, National Taiwan University, No. 1, Sec. 1, Jen-Ai Road, Taipei 10051, Taiwan

${ }^{2}$ Center of Precision Medicine, National Taiwan University, Taipei, Taiwan
}

respiration oxidizes organic compounds to $\mathrm{CO}_{2}$ and $\mathrm{H}_{2} \mathrm{O}$. The outer and the inner membranes (OM and IM) define two mitochondrial compartments: intermembrane space (IMS) and the central matrix. Oxidative phosphorylation (OXPHOS) is powered by the movement of electrons through the ETC (electron transport chain) complex I, II, III, and IV to generate a gradient of concentration of protons maintained in the IMS. The electrochemical proton gradient across the IM energizes ATP production by the complex $\mathrm{V} \mathrm{F}_{1}-\mathrm{F}_{0}$ ATP synthase [8]. The $\mathrm{F}_{0}$ is a hydrophobic segment that spans the IM, which is the channel for the transport of protons from the IMS back into the matrix. The energy of this process also converts ADP and Pi into ATP in the $F_{1}$ complex which resides in the matrix.

Mitochondria contain their genome. They divide by binary fission, similar to bacteria. Yeast mtDNA represents on average $15 \%$ of the total cellular DNA content [9] and consists mostly of linear molecules with varying lengths ranging from 75 to $150 \mathrm{~kb}$ [10]. In

(c) The Author(s). 2021 Open Access This article is licensed under a Creative Commons Attribution 4.0 International License, which permits use, sharing, adaptation, distribution and reproduction in any medium or format, as long as you give appropriate credit to the original author(s) and the source, provide a link to the Creative Commons licence, and indicate if changes were made. The images or other third party material in this article are included in the article's Creative Commons licence, unless indicated otherwise in a credit line to the material. If material is not included in the article's Creative Commons licence and your intended use is not permitted by statutory regulation or exceeds the permitted use, you will need to obtain permission directly from the copyright holder. To view a copy of this licence, visit http://creativecommons.org/licenses/by/4.0/ The Creative Commons Public Domain Dedication waiver (http://creativecommons.org/publicdomain/zero/1.0/) applies to the data made available in this article, unless otherwise stated in a credit line to the data. 
Saccharomyces cerevisiae, mtDNA encodes eight proteins, of which seven are subunits of the ETC and OXPHOS, and one is a ribosomal small subunit protein [11]. Interestingly, most mtDNA genes are conserved from yeast to humans [12]. mtDNA is considered a major target for aging-associated somatic mutations due to the oxidative microenvironment of mitochondria, lack of protective histones, and limited efficiency of the mtDNA repair mechanisms compared to those of nuclear DNA [13]. mtDNA integrity is maintained by its binding proteins $[14,15]$ and the excision repair system [16]. However, reactive oxygen species [17], drug, temperature, DNA polymerase $\gamma$ mutations, disturbance of mitochondrial membrane potential $\left(\Delta \psi_{\mathrm{m}}\right)$, imbalance of proteases, and aging can change the integrity of mtDNA [18-22]. Under stress, mtDNA can also escape to intracellular or extracellular compartments, triggering intrinsic apoptosis and/or innate immune inflammatory response [23].

Chaperone systems play prominent roles in maintaining proteostasis. The heat shock protein (HSP) HSP70 and HSP90 systems are the main chaperone machinery for cellular protein folding [24] and misfolded proteins create pathological problems in different tissues. Protein aggregates are found in a variety of diseases, including type II diabetes, Parkinson's, and Alzheimer's diseases [25]. In addition to chaperones, the specificity of protein folding machines largely depends on cochaperones. They actively participate in various stages of the folding cycle [26]. Cochaperones bind to specific domains of HSPs to stabilize their conformation or modulate their functions. Besides, each cochaperone recruits its specific clients to the folding system [27]. Therefore, both chaperones and cochaperones control folding and proteostasis.

A previous study demonstrates crosstalk among three hallmarks of aging: deregulated nutrient sensing, loss of proteostasis, and mitochondrial dysfunction [28]. The HSP90 cochaperone Ids2 enhances HSP90's chaperone activity during calorie restriction, enabling cells to maintain protein quality for sustained longevity. Ids2 can stimulate the ATPase activity of HSP90. Surprisingly, deletion of IDS2 causes a severe growth defect in glycerol [28], but the detailed mechanisms are still unclear. Here, we developed a screening procedure from $\mathrm{Hsc} 82$ physical interactors to discover the first direct client of the HSP90-Ids2 chaperone complex and reveal the mechanism of Ids2 in maintaining mtDNA integrity and mitochondrial functions.

\section{Results}

\section{Deletion of HSC82 or IDS2 causes a deficiency in} mitochondrial functions

We previously showed that Ids2 serves as a cochaperone of Hsc82, the major HSP90 in yeast, to maintain protein quality for cell longevity [28]. Interestingly, the growth defect of the $h s c 82 \Delta$ and $i d s 2 \Delta$ cells in glycerol medium [28] was not observed in the HSP82, a paralog of HSC82, deleted cells (Additional File 1: Figures S1). We speculate that the growth defect of the $h s c 82 \Delta$ and $i d s 2 \Delta$ cells may be caused by the loss of mitochondrial functions. To analyze the mitochondrial functions, we used fluorescent dyes to determine their $\Delta \psi_{\mathrm{m}}$, production of ROS, and mitochondrial mass $[29,30]$. Deletion of HSC 82 or IDS2 decreased the $\Delta \psi_{\mathrm{m}}$, as observed by microscopic imaging and flow cytometry analyses (Fig. 1A). The fluorescence of the ROS-sensitive probe DHE decreased significantly in stationary phase $h s c 82 \Delta$ and $i d s 2 \Delta$ cells (Fig. 1B). To know whether the loss of $\Delta \psi_{\mathrm{m}}$ and ROS production were due to the loss of mitochondrial function or the whole organelle, we used NAO staining to detect mitochondrial mass [31] in both fermentative (glucose) and respiratory (glycerol) growth. Under fermentative growth, the mitochondrial mass did not show a significant difference among wildtype, $h s c 82 \Delta$, and $i d s 2 \Delta$ stains. In respiratory growth, wild-type cells showed a slight increase in mitochondrial mass. However, the mitochondrial mass was decreased $30 \%$ in $h s c 82 \Delta$ and $i d s 2 \Delta$ cells (Fig. 1C), indicating that $h s c 82 \Delta$ and $i d s 2 \Delta$ cells may have defective mitochondrial biogenesis [32]. The loss of $\Delta \psi_{\mathrm{m}}$ implies that $h s c 82 \Delta$ and $i d s 2 \Delta$ cells may have a defect in the respiratory chain [33]. To test this hypothesis, we tested oxygen consumption in wild-type, $h s c 82 \Delta$, and $i d s 2 \Delta$ cells. As expected, the oxygen consumption was decreased by $90 \%$ in $h s c 82 \Delta$ and $i d s 2 \Delta$ cells, suggesting a severe defect in the respiratory chain (Fig. 1D). These results indicate that Hsc82 and Ids2 are essential for intact mitochondrial function.

\section{Ids2 maintains the stability of the assembly factor of cytochrome coxidase and ATP synthase}

To understand how the loss of Ids2 causes mitochondrial dysfunction and defective cellular respiration, we screened for the non-essential proteins that physically interact with $\mathrm{Hsc} 82$, proteins in mitochondria, and genes required for respiratory growth from SGD (Fig. 2A and Additional File 2: Table S1). According to these three criteria, $607 \mathrm{Hsc} 82$ interacting proteins were narrowed down to 20 potential clients: Aco1, Acs1, Adk1, Atp1, Atp2, Atp3, Ccs1, Cor1, Coa3, Dcs1, Fum1, Gpm1, Mir1, Ndi1, Pet9, Por1, Qcr2, Sod1, Tuf1, and Vps1. According to Gene Ontology term analysis (Additional File 3: Table S2), most of the 20 potential clients were associated with ATP metabolic process (Adk1, Atp1, Atp2, Atp3, Gpm1, Ndi1, and Qcr2) and cellular respiration (Aco1, Cor1, Fum1, Ndi1, Pet9, Qcr2, and Sod1). The potential candidates were further tested for their protein stabilities in the $h s c 82 \Delta$ and ids $2 \Delta$ background at $30{ }^{\circ} \mathrm{C}$ and $37{ }^{\circ} \mathrm{C}$, except for three genes not available in both TAP- and GST-tagged libraries (Dsc1, Tub1 and Vps1). Only complex IV cytochrome c oxidase assembly factor 


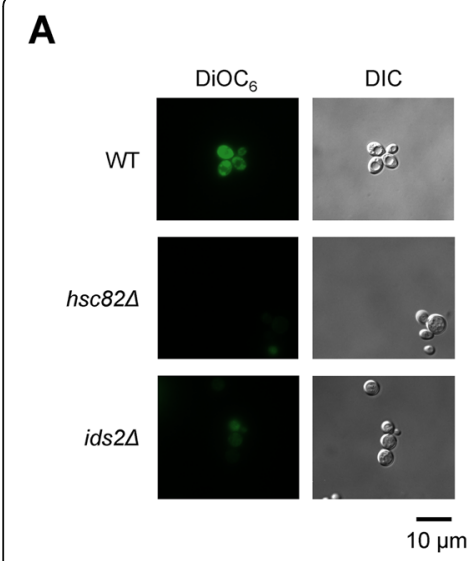

C

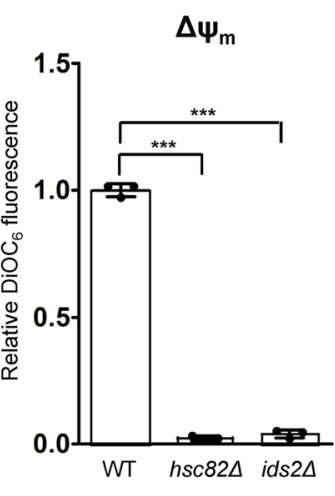

B
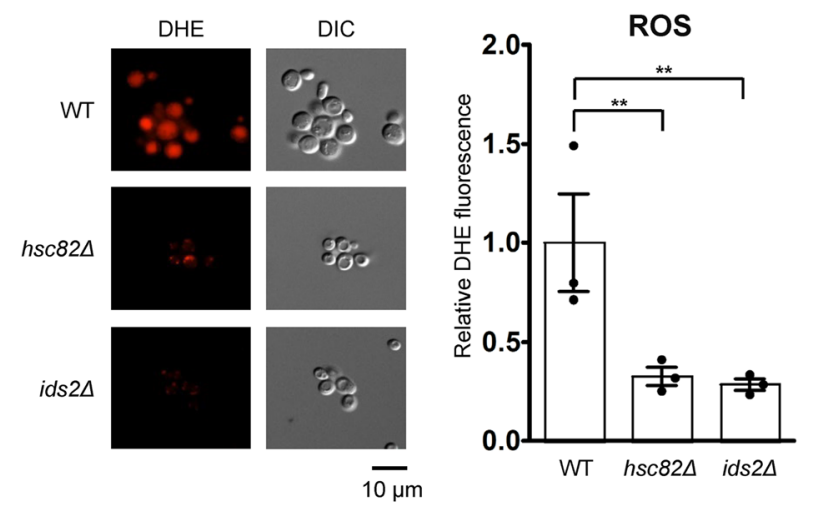

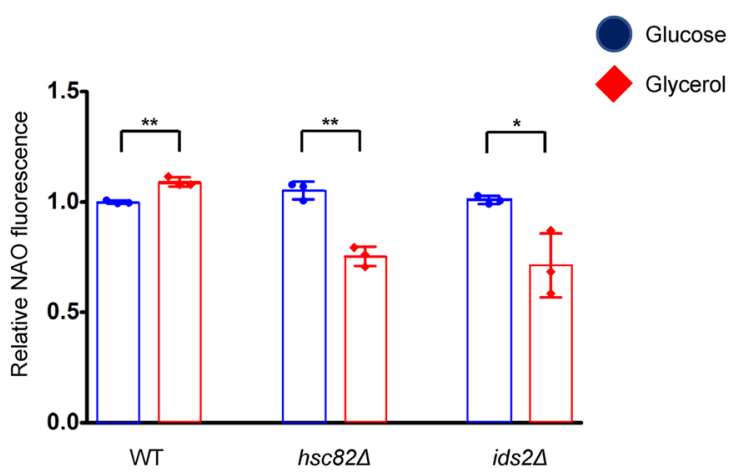

D

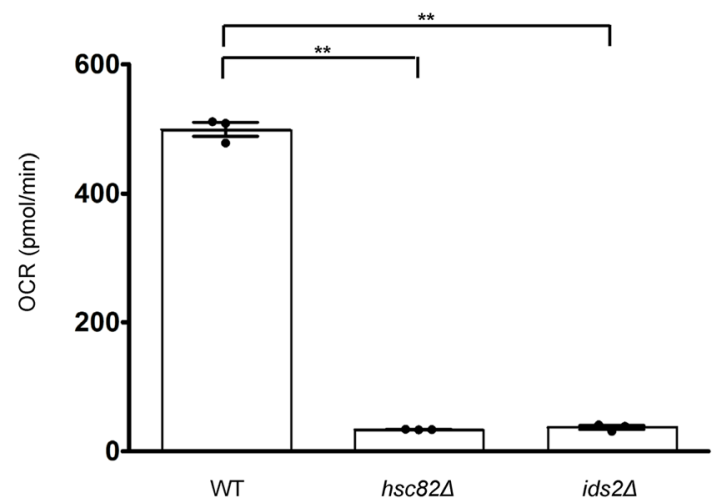

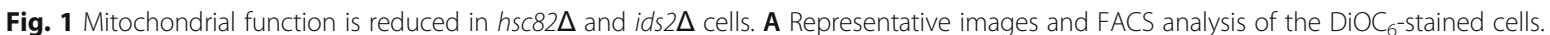
Indicated strains were cultured in YEPG medium for $48 \mathrm{~h}$. The $\Delta \psi_{\mathrm{m}}$ was detected by FACS analysis after $30 \mathrm{~min}$ of DiOC 6 staining. The DiOC 6 fluorescence value was normalized to that of the wild-type strain. B Representative images and FACS analysis of the DHE-stained cells. Indicated strains were cultured in YEPD medium for $48 \mathrm{~h}$. The intracellular levels of ROS generated in the indicated strains were examined by FACS analysis after 10 min of DHE staining. The DHE fluorescence value was normalized to that of the wild-type strain. $\mathbf{C}$ Mitochondrial mass of indicated strains cultured in YEPD or YEPG for $48 \mathrm{~h}$ were detected by FACS analysis after NAO staining. The NAO fluorescence value was normalized to that of the wild-type strain in the glucose medium. D The oxygen consumption rate of each strain was measured by a Seahorse XF Analyzers. The values are mean $\pm \mathrm{SD}(n=3)$ and compared by using Student's $t$ test. ${ }^{*}, p$ value $<0.05 ;{ }^{* *}, p$ value $<0.01$; and ${ }^{* * *}, p$ value $<0.001$. Points on bar graphs indicate individual data values from each biological replicate

Coa3 and complex V ATP synthase subunits Atp1, Atp2, and Atp3 were markedly downregulated (Fig. 2B), while others did not exhibit a substantial decrease in the hsc $82 \Delta$ and ids $2 \Delta$ cells (Fig. $2 \mathrm{C}$ and Additional File 1: Figures S2). The mRNA levels of these potential clients were not reduced in $30{ }^{\circ} \mathrm{C}$ (Additional File 1: Figures S3). These findings suggest that Ids2 maintains the stability of cytochrome c oxidase assembly factor and ATP synthase subunits, and the alteration of the protein amounts is not regulated at the transcriptional level.

Suppression of Hsc82, Ids2, and Atp3 causes ETC damage, petite formation, and mtDNA loss

ETC generates a proton gradient across the IM by pumping protons into the IMS, which drives the synthesis of ATP via coupling with OXPHOS with ATP synthase [34].
Dramatically, all of the four potential clients were located in the ETC (Fig. 3A), and deletion of each of them showed growth defect under glycerol condition (Fig. 3B). Besides, ATP production was significantly reduced in $h s c 82 \Delta$ and ids $2 \Delta$ cells (Fig. $3 \mathrm{C}$ ). To further prove the deficiency in ETC, we checked the respiration-deficient petite colonies and mtDNA in atp $1 \Delta$, atp $2 \Delta$, atp $3 \Delta$, and coa3 $\Delta$ cells. Strikingly, only atp $3 \Delta$, but not atp $1 \Delta$, atp $2 \Delta$, and, coa3 $\Delta$ showed severe petite phenotype (Fig. 3D) and complete loss of mtDNA (Fig. 3E), as observed in the $h s c 82 \Delta$ and ids $2 \Delta$ cells. These results demonstrate that only ATP3 deficiency causes similar mitochondrial phenotypes as the hsc $82 \Delta$ and ids $2 \Delta$ cells.

\section{Atp3 is a client of Ids2}

To confirm whether these four candidates are direct clients of Ids2, we analyzed their interactions with Ids2 


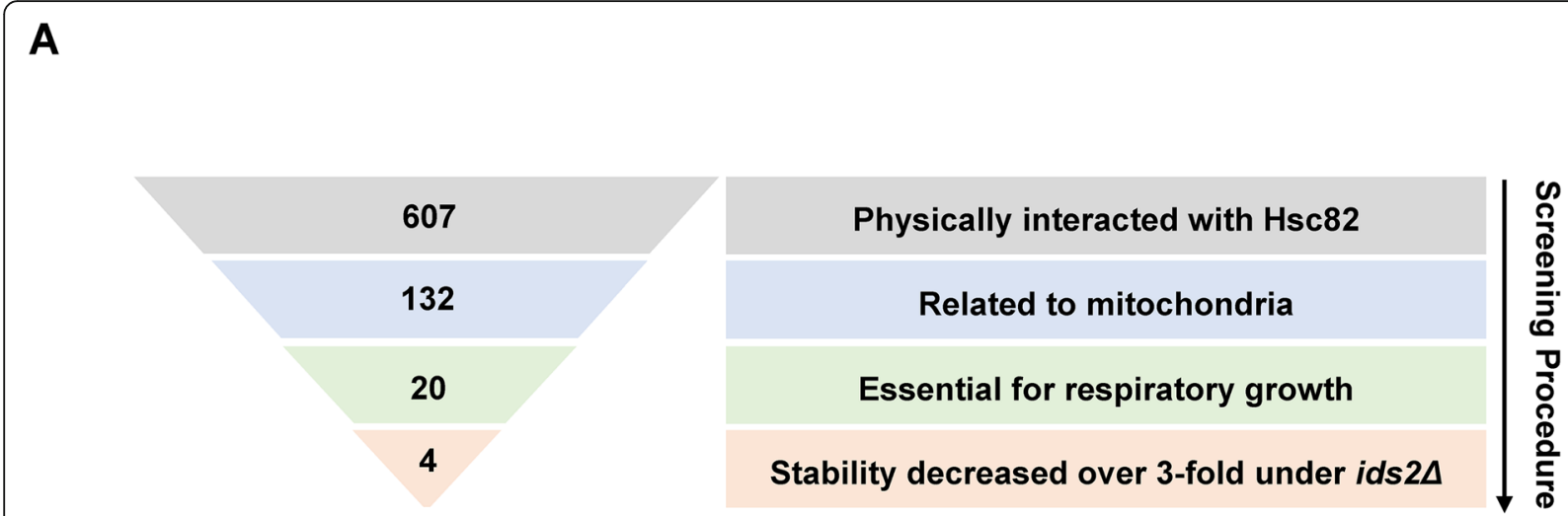

B

\section{C}

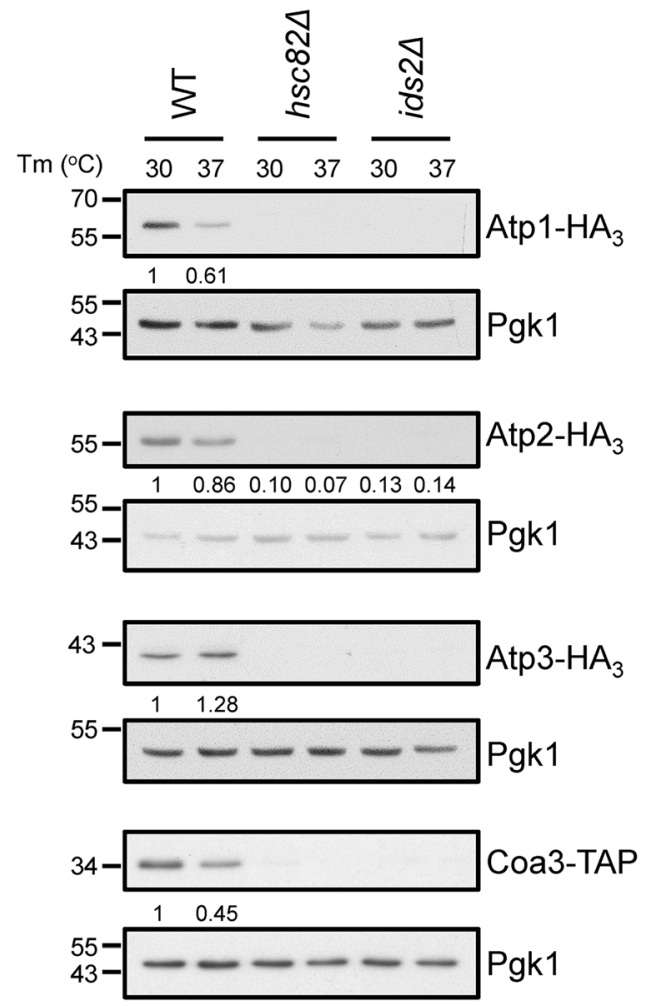

(kDa)

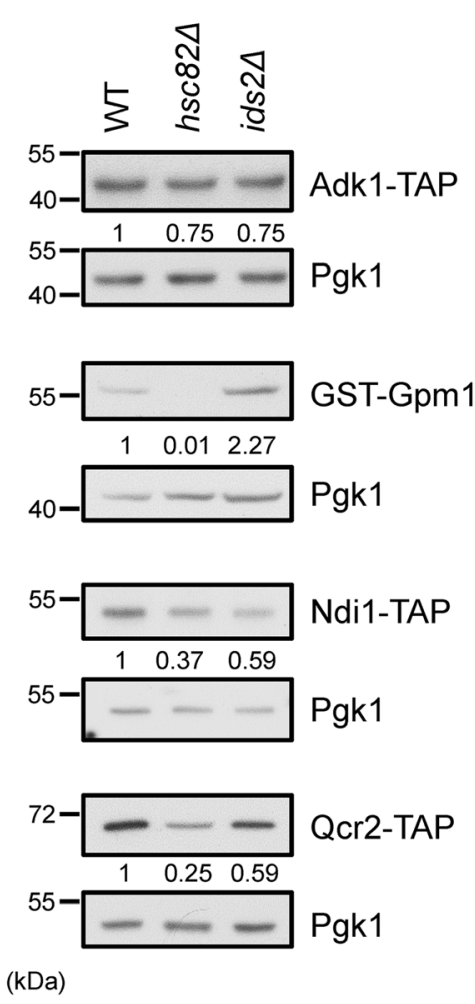

Fig. 2 A screen for the clients regulated by the Hsc82-Ids2 chaperone complex. A A schematic diagram highlights the steps in the screening of the Hsc82-lds2 clients. B Ids2 maintains the protein levels of four candidates in the ATP metabolic process. Overnight cells of the indicated strains were refreshed to $\mathrm{OD}=0.5$ and then transferred to 30 or $37^{\circ} \mathrm{C}$ for $3 \mathrm{~h}$. Total protein was extracted, and the western blot was hybridized with various antibodies. Pgk1 was served as a loading control. The numbers below are the means $(n=3)$ of the intensity ratios of HA/Pgk1 compared with that of the wild-type strain. $\mathbf{C}$ Ids2 does not control the stability of the other four candidates in the ATP metabolic process. Overnight cells of the indicated strains were refreshed to $\mathrm{OD}=0.5$ in $30^{\circ} \mathrm{C}$ for $3 \mathrm{~h}$. Western blotting was conducted as described above both in vivo and in vitro. A co-immunoprecipitation assay showed that Atp1 and Atp3 interacted with Ids2 in vivo (Fig. 4A). Similar results were observed in in vitro pulldown assay where Atp1 and Atp3 displayed a mild and strong association with Ids2, respectively
(Fig. 4B). To further define the major mitochondriarelated client, we transformed the pRS414-ATP1 or pRS414-ATP3 plasmid into the ids2 $\Delta$ cells to complement the glycerol growth defect. Only the Atp3, but not Atp1, could complement the deficiency of Ids2 (Fig. 4C). 
A
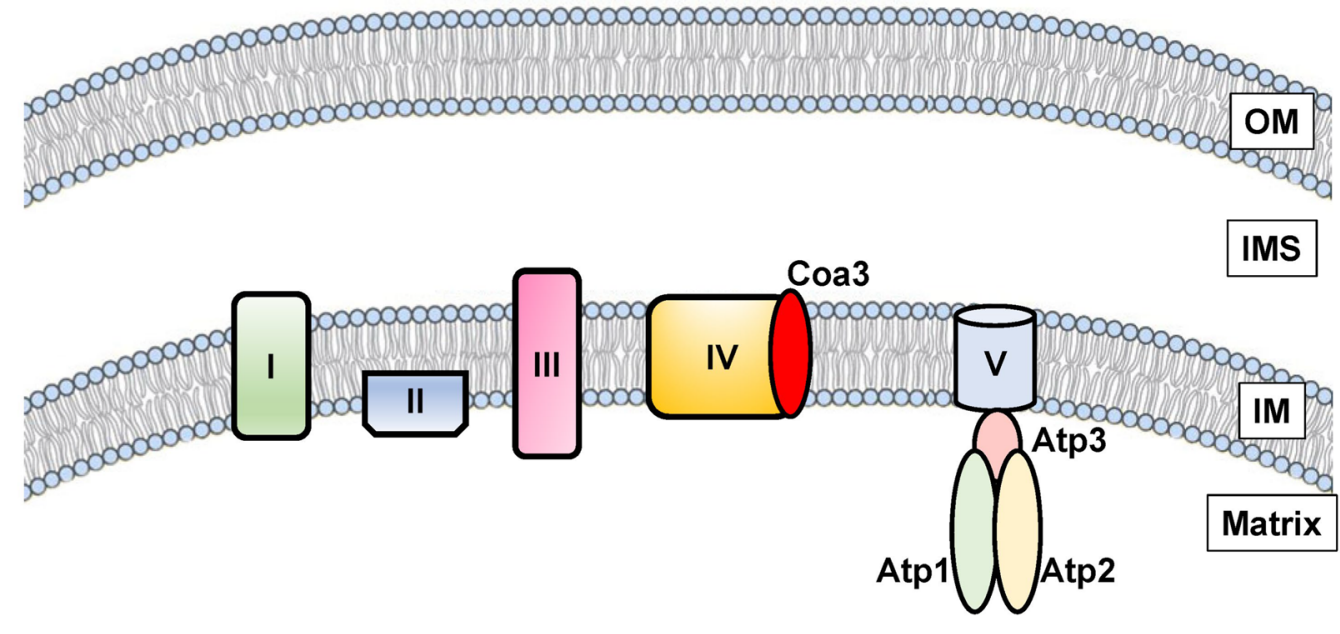

B

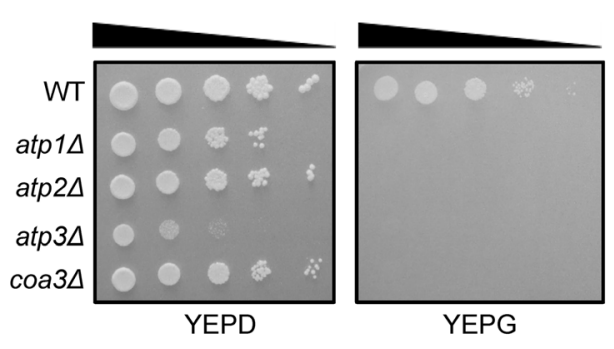

D


C

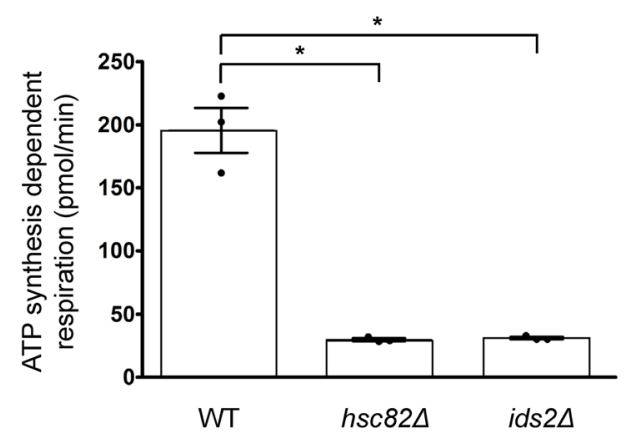

E

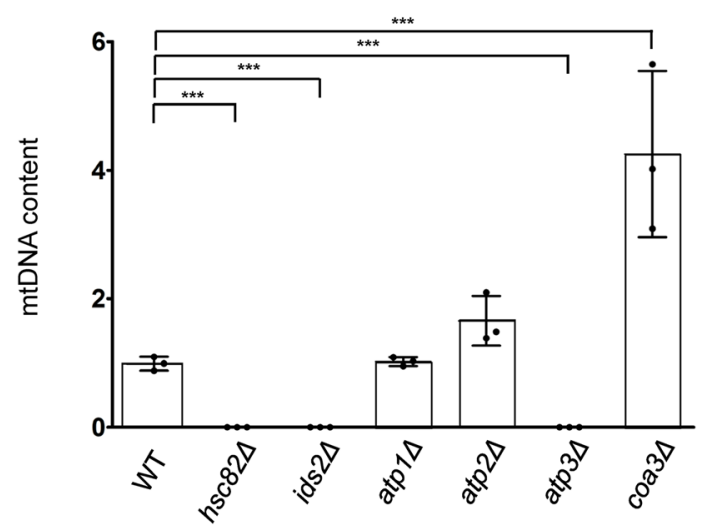

Fig. 3 (See legend on next page.) 


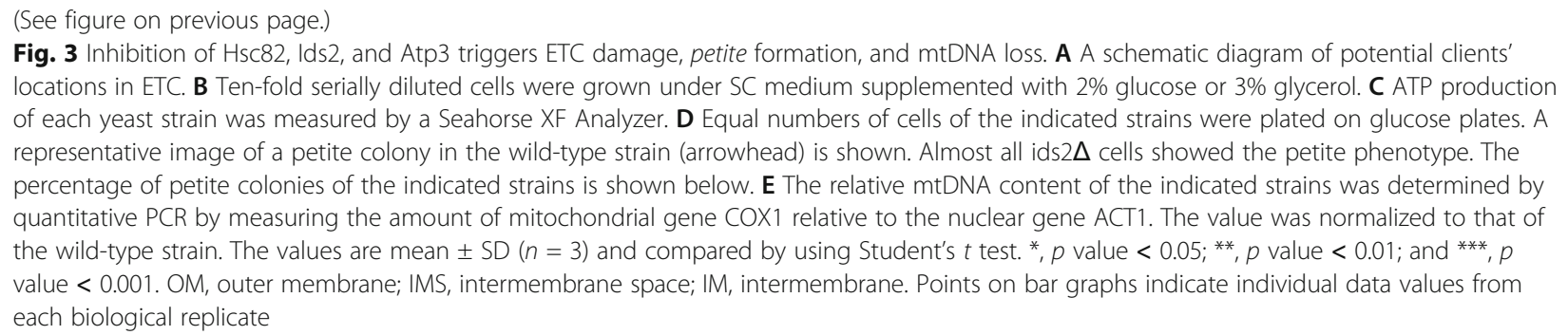

These data suggest that Atp3 may be a key client of Ids2 and the stability of other complex $\mathrm{V}$ candidates in $i d s 2 \Delta$ cells might be reduced by the loss of Atp3. To test this possibility, we examined the protein stability of these candidates under the elimination of one of the candidates (Additional File 1: Figures S4A-C). Interestingly, deletion of ATP3 reduced the protein level of Atp1 and Atp2, and deletion of ATP1 or ATP2 also decreased the level of Atp3. And a co-immunoprecipitation assay observed that Atp3 co-precipitated with Ids2 and HSP90 (Additional File 1: Figures S4D), indicating that Atp3HSP90-Ids2 may form a ternary complex. All these results suggest that Atp3 may be a major client of Ids2. To understand where Ids2 interacts with Atp3 in cells, confocal microscopic images of Ids2 were captured. Ids2GFP distributed in cytosol, which was separated from the mitochondrial IM protein Cox4-DsRed (Fig. 4D), implying that Ids2 may interact with Atp3 in the cytosol or near the mitochondrial OM.

\section{A middle motif in Ids2 recruits the $\mathrm{N}$-terminal Atp3 to the folding system}

To understand how Ids2 recruits its client Atp3, multiple truncated proteins were tested for the Ids2-Atp3 interaction. Ids2 was truncated to $\mathrm{N}$-terminal (amino acid 1-92), middle (aa 92-256) and C-terminal (aa 256469) regions, and Atp3 was truncated to $\Delta \mathrm{N}$ (1-91 deletion), $\Delta \mathrm{M}$ (91-225 deletion), and $\Delta \mathrm{C}$ (225-311 deletion) forms (Additional File 1: Figures S5). To test the direct interaction, we purified the recombinant proteins of each fragment from $E$. coli. The pulldown results indicated that the middle domain of the Ids2 interacts with the N-terminus of Atp3 (Fig. 5A-D). According to the previous study [28], Hsc82 also interacts with the middle region of Ids2, and the Hsc82-Ids2 interaction is regulated by the phosphorylation of Ids2 S148. However, a co-immunoprecipitation assay demonstrated that the interaction between Atp3 and Ids2 S148 mutants displayed no significant difference comparing with that of the Ids2 wild-type strain (Additional File 1: Figures S6A), implying that the motif interacting with Atp3 on Ids2 is distinct from that with Hsc82. These results identify the domain requirement for Ids2 to recruit Atp3 to the folding system.
To further define the motif of Ids2 that recruits its client to the folding system, the homologs of Ids2 were aligned and three conserved motifs in the middle region of Ids2 were subjected to mutagenesis and analysis (ids2-E127A, A129G, ids2-A201G, L209A, and ids2$W 219 A$, E225A, Additional File 1: Figures S5A). Interestingly, the $i d s 2-A 201 G, L 209 A$ cells exhibited growth defects under glycerol condition (Fig. 6A) and Atp1 and Atp3 were also markedly lost in the ids2-A201G, L209A cells (Fig. 6B and Additional File 1: Figures S6B). Analysis of the secondary structure by the CFSSP program [35] identified an $\alpha$-helix spanning aa 196 211 of Ids2 which covers the mutated A201 and L209 residues (Additional File 1: Figures S5A), implying that this helix may be crucial for the Ids2 cochaperone to recruit its client.

To understand how an Ids2 client is attracted to the folding system, we next examined the Atp3 sequence. Alignment and secondary structure analyses of the Atp3 homologs identified an $\alpha$-helix at the $\mathrm{N}$-terminal region of Atp3 spanning from aa 31 to 89 (Additional File 1: Figures $\mathrm{S} 5 \mathrm{~B}$ ). We generated two mutational strains to destroy the front (atp3-41RLKS to $A A A A$ ) and the rear (atp3-66KAEK to $A E A A$ ) motifs of the $\alpha$-helix, respectively Additional File 1: Figures S5B). Both atp3-41RLKS to $A A A A$ and atp3-66KAEK to $A E A A$ cells exhibited growth defects under glycerol condition (Fig. 6C), but Atp3-41RLKS to AAAA protein was more unstable than Atp3-66KAEK to AEAA protein (Fig. 6D). In vitro pulldown assay of Ids2 and Atp3 mutants also showed a reduction of the Ids2-Atp3 interaction (Additional File 1: Figures $\mathrm{S6C}$ ). These results imply that the front region of the N-terminal $\alpha$-helix of Atp3 may be critical in Ids2-mediated Atp3 recruitment (Fig. 6E).

\section{Mitochondrial Yme1 and Pim1 proteases are essential for Atp3 quality control}

Proteostasis highly relies on chaperones and proteases to maintain proper folding and remove unfolded proteins. Cytoplasmic proteins can be degraded by the proteasome and the vacuolar proteolysis degradation pathways [36]. On the other hand, mitochondrial subcompartments are under surveillance of ATP-dependent proteases for unfolded and unassembled proteins [17]. 


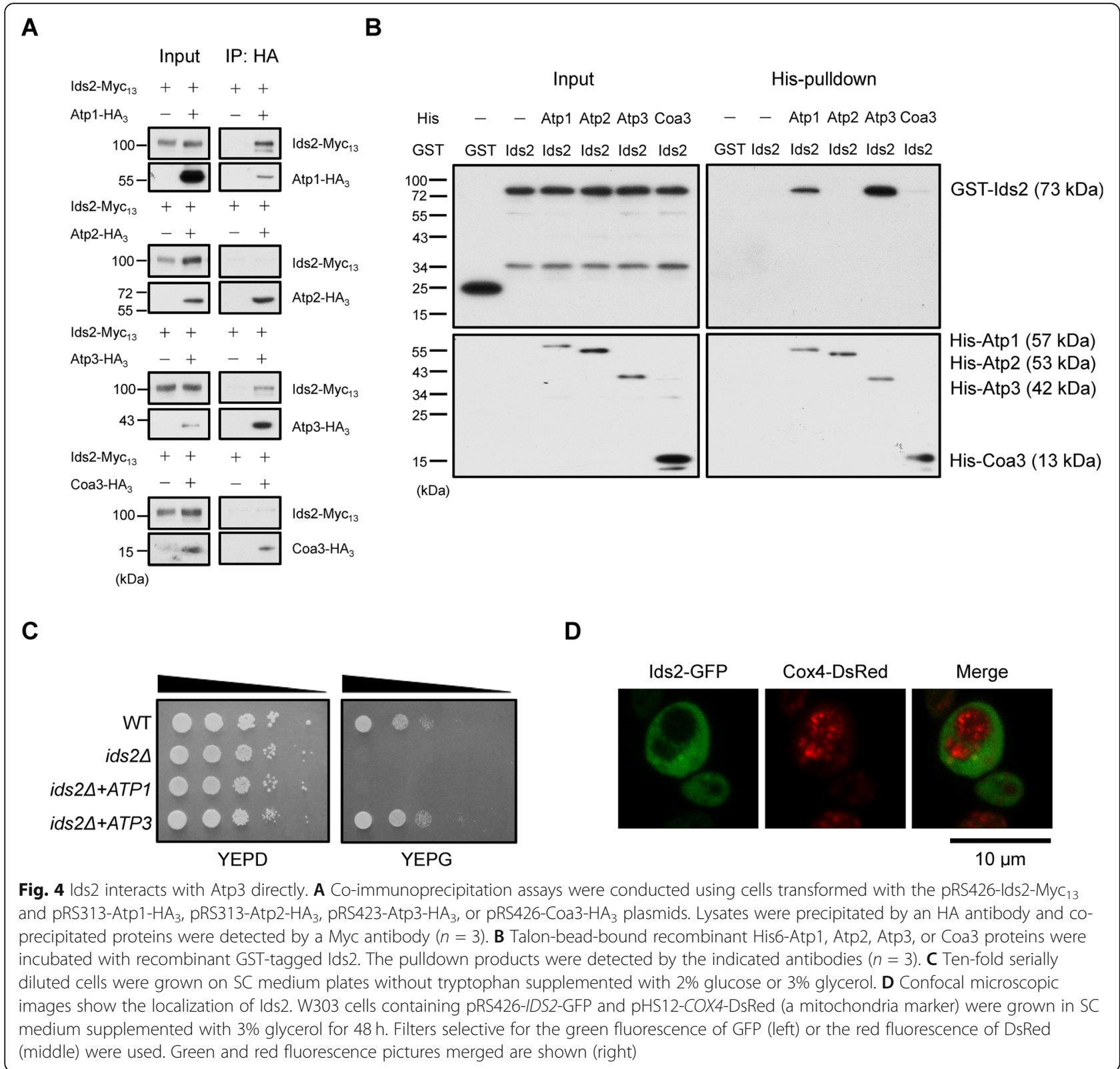

To understand the protease pathways controlling the quality control of Atp3 when the HSP90/Ids2 system fails to execute its folding function, we checked whether the vacuolar protease Pep4 [37], IMS/IM protease Yme1, IM/matrix protease Yta10 [38], and matrix protease Pim1 [39] modulate the Atp3 protein level in the absence of Ids2 (Fig. 7A). Interestingly, YME1 or PIM1 deletion could rescue the Atp3 level in the ids $2 \Delta$ cells (Fig. $7 \mathrm{~B}$ and Additional File 1: Figures S7B), suggesting that Yme1 and Pim1 control the amount of Atp3. And deletion of IDS2 did not change the ratio of Atp3 inside mitochondria (Additional File 1: Figures S7C). However, only the YME1 deletion could rescue the growth defect of ids $2 \Delta$ cells in the glycerol medium (Fig. 7C). These results imply that undegraded Atp3 might not be able to recover the unbalanced mitochondrial function under the loss of protease Pim1. Because Atp3 is completely undetectable in the ids $2 \Delta$ cells, to study the conformational difference of Atp3 in wild-type and ids $2 \Delta$ cells, we collected undegraded Atp3 from pim1 1 and ids $2 \Delta$ pim1 $1 \Delta$ strains by immunoprecipitation followed with limited Proteinase K-mediated proteolysis. Interestingly, Atp3 in the ids $2 \Delta$ pim1 $\Delta$ strain was more sensitive to proteolytic digestion compared with that in the pim1 1 strain (Additional File 1: Figures S7D). These results suggest that absence of Ids2 may alter the conformation of Atp3, thereby rendering it more susceptible to proteolytic digestion. 


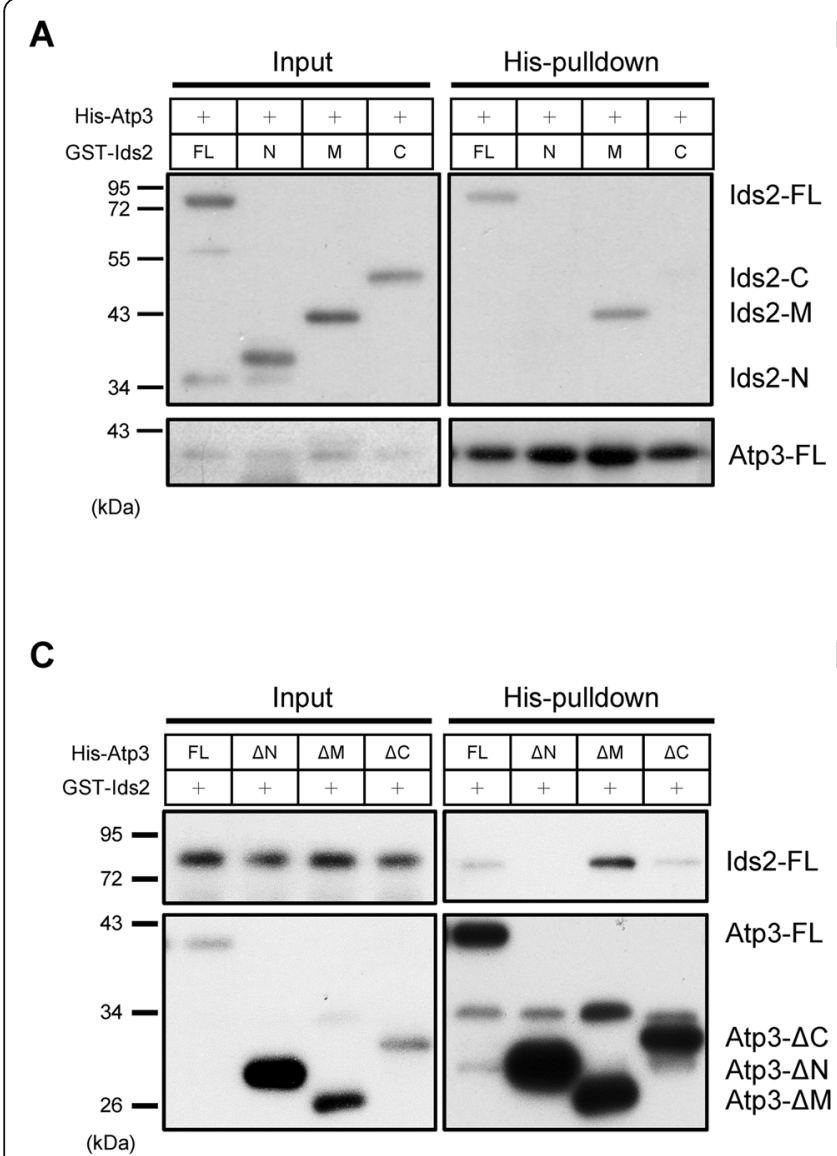

B

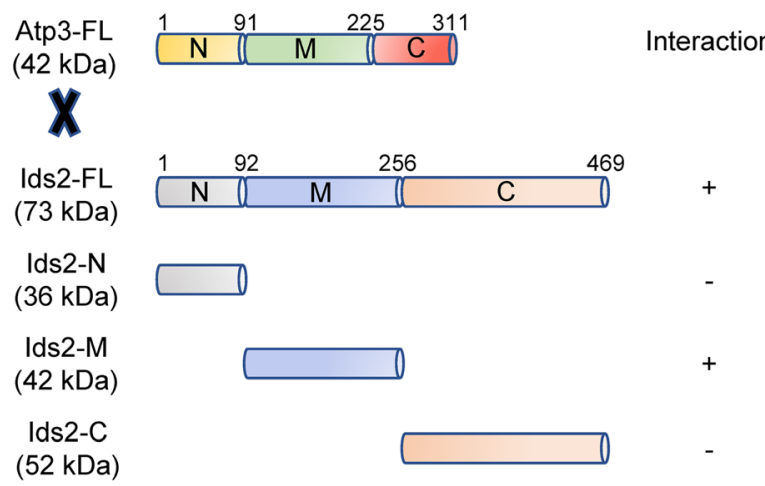

D

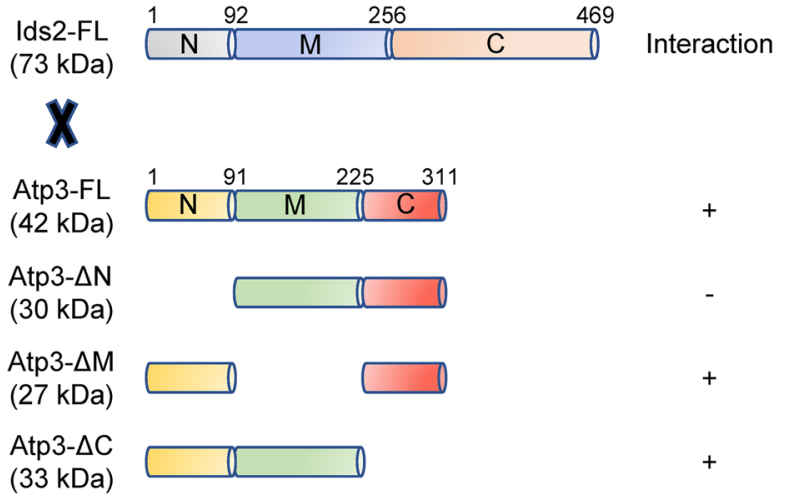

Fig. 5 Domain requirement for the Ids2-Atp3 interaction. A Talon-bead-bound His 6 -Atp3 proteins were incubated with full-length or truncated Ids2 recombinant proteins $(n=3)$. The pulldown assay was conducted as described in Fig. 4. B A schematic diagram of Atp3 and various Ids2 truncations. C Talon-bead-bound full-length or truncated His ${ }_{6}$-Atp3 were incubated with full-length Ids2 recombinant proteins $(n=3)$. The pulldown assay was conducted as described above. D A schematic diagram of Ids2 and various Atp3 truncations

Ids2 is a mitochondria-dominant HSP90 cochaperone induced in the glycerol medium

Given that Ids2 is essential for mitochondria function, we asked whether Ids2 is a mitochondria-dominant HSP90 cochaperone induced under the requirement of oxidative respiration. A major cytoplasmic HSP90 cochaperone is Aha1, which also binds to the middle domain of HSP90 [40] and promotes Hsc82 ATPase activity as Ids2 [28]. We, therefore, compared the growth of wild-type, $h s c 82 \Delta$, ids $2 \Delta$, and aha1 $\Delta$ cells in the glycerol medium. Interestingly, aha1 $\Delta$ cells did not exhibit a growth defect in glycerol (Additional File 1: Figures S8A). Atp3 was also stably maintained in the aha1 $\Delta$ cells (Additional File 1: Figures S8B). In contrast, Ids2 was highly expressed in the glycerol medium (Additional File 1: Figures S8C). These results suggest that Ids2 is more important for mitochondrial function than cytoplasmic HSP90 cochaperone Aha1.

\section{Discussion}

The proton-pumping complexes of the ETC produce and maintain an electrochemical proton gradient across the membrane that energizes ATP production by ATP synthase. ATP synthase consists of the IM-bound $\mathrm{F}_{0}$ region and the matrix-exposed $F_{1}$ region. Atp3, the $\gamma$ subunit of ATP synthase, is the central subunit connecting $\mathrm{F}_{1}$ and $\mathrm{F}_{0}$ for the integrity of the ATP synthase [41]. Here we define a proteostasis system of the ATP synthase. The absence of the Hsc82-Ids2 complex may lead to Atp3 misfolding (Fig. 8). Without Atp3, ATP synthase assembly is disrupted, which leads to proton accumulation in the IMS. A continuously increasing proton concentration in the IMS may disturb the IM lipid bilayer, rise mitochondrial membrane permeability, and eventually induce a non-specific pore across the IM which could permit free distribution of mtDNA [42, 43]. 


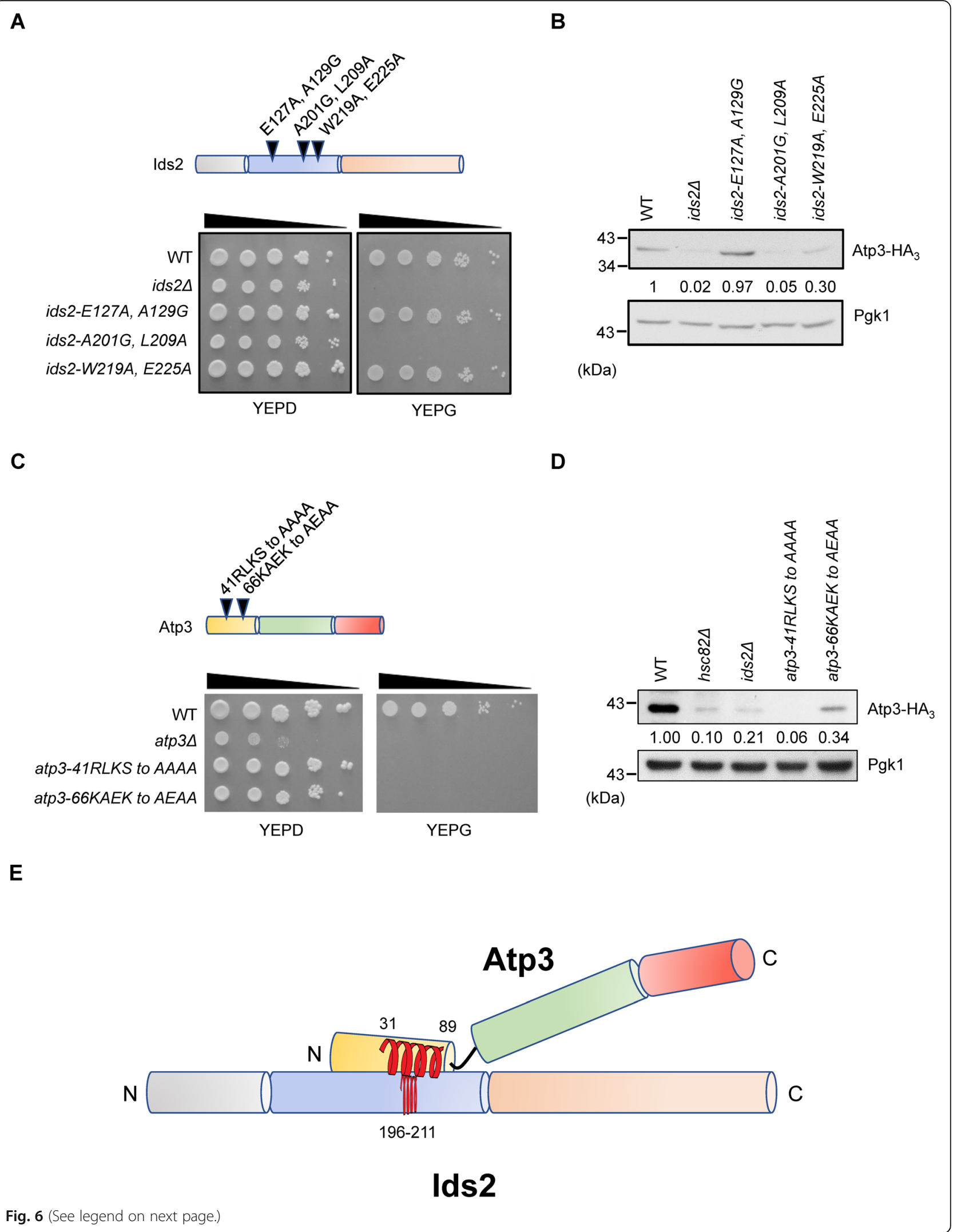


(See figure on previous page.)

Fig. 6 The Ids2 (196 211) and Atp3 (31 89) motifs are critical for the Ids2-Atp3 association. A Upper panel shows a schematic diagram of the Ids2 mutations. The ten-fold serially diluted ids 2 mutants were grown on SC plates supplemented with $2 \%$ glucose or $3 \%$ glycerol. B Indicated strains containing the pRS313-Atp3- $\mathrm{HA}_{3}$ plasmid were cultured overnight and then refreshed to OD $=0.5$. Total proteins were extracted, and the Atp3- $\mathrm{HA}_{3}$ protein levels in these ids2 mutants were detected by western blotting. $\mathbf{C}$ A schematic diagram of the Atp3 mutations and the ten-fold serial dilution of atp3 mutants growing on SC plates supplemented with $2 \%$ glucose or $3 \%$ glycerol. D The mutated Atp3-HA 3 p plasmids were transformed into wild-type cells. The Atp3 protein levels were detected by western blotting. The numbers below are the means $(n=3)$ of the intensity ratios of HA/Pgk1 compared with that of the wild-type strain. Tagged wild-type Atp3 in $h s c 82 \Delta$ or ids $2 \Delta$ cells were used as negative controls. E A cartoon indicates that an Atp3 (31 89) motif interacts with an Ids2 (196 211) motif

A

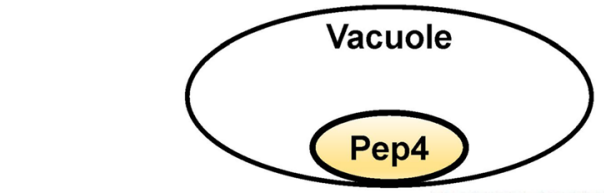

\section{Cytosol}

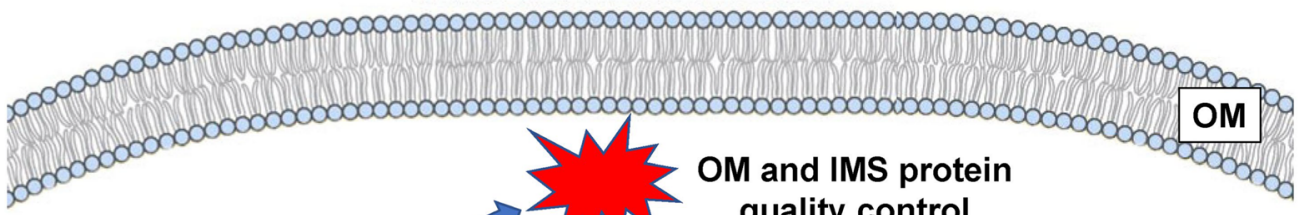
quality control

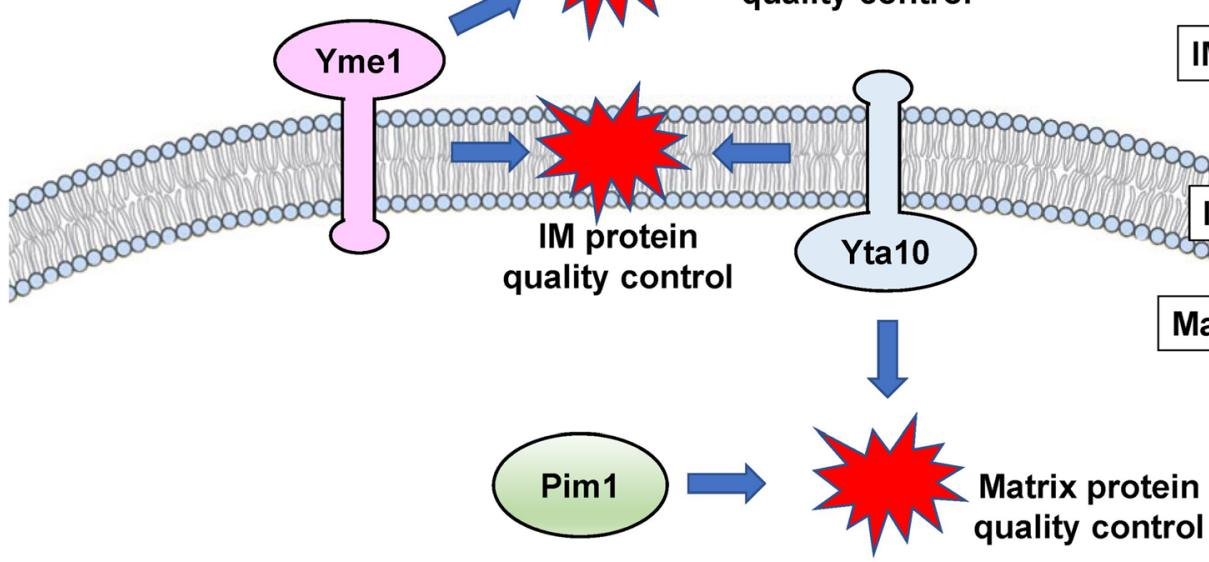

IMS

B

C


Fig. 7 Protein quality control of Atp3. A A schematic diagram of various proteases in the cytosol and different compartments of mitochondria. B The protein levels of Atp3- $\mathrm{HA}_{3}$ in indicate strains were detected by western blotting. The numbers below are the means $(n=3)$ of the intensity ratios of HA/Pgk1 compared with that of the wild-type strain. C Ten-fold serially diluted cells were grown on YEP plates supplemented with $2 \%$ glucose or $3 \%$ glycerol 


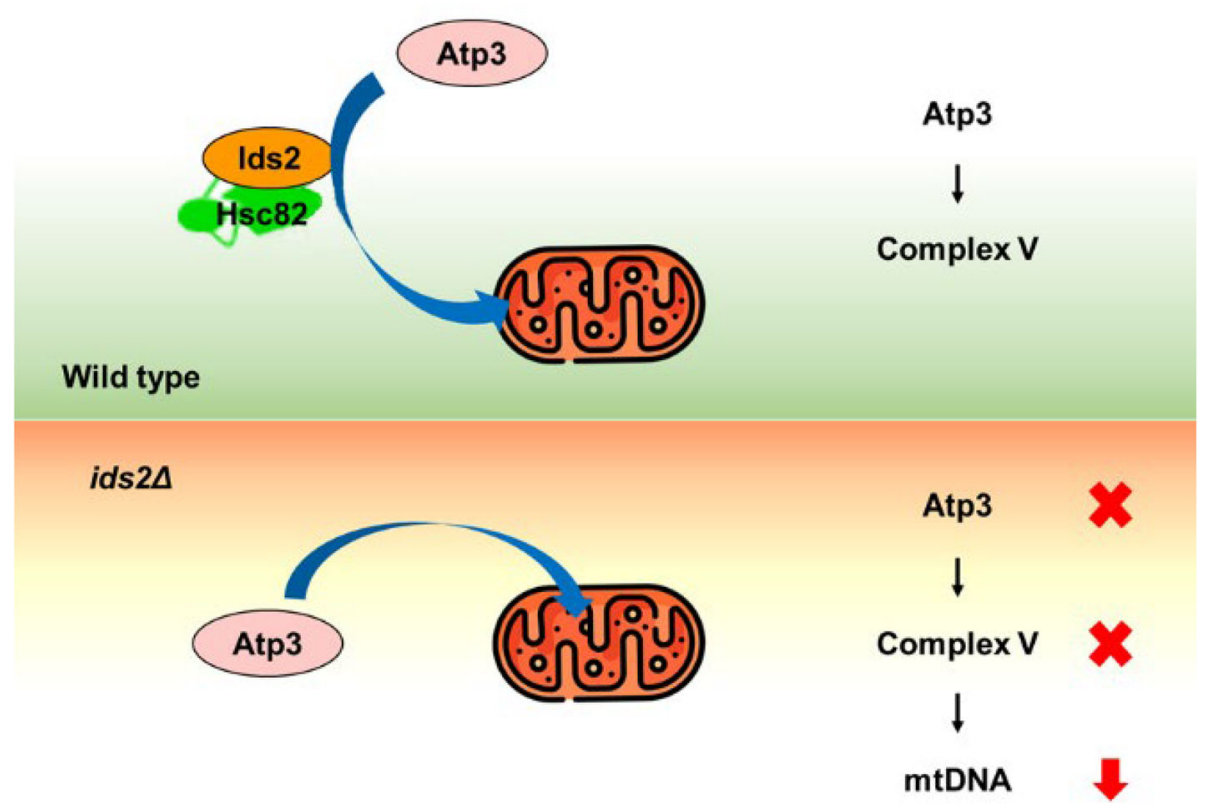

Fig. 8 A proposed model of how the Hsc82-Ids2 chaperone complex regulates mtDNA and mitochondrial functions. Atp3 may be folded by the Hsc82-lds2 chaperone complex before being imported into mitochondria. However, in ids2 $\Delta$ cells, Atp3 may be degraded and incompletely assembled complex $\mathrm{V}$ may prevent protons from flowing across the IM. To overcome the stress of continuously increasing proton concentration in IMS, mitochondria may eliminate mtDNA to disrupt ETC and stop proton accumulation

Most yeast mitochondrial proteins are encoded by nuclear genes, synthesized in cytoplasmic ribosomes, and then imported into the organelle [44]. The newly synthesized polypeptides first contact the mitochondrial OM via $\mathrm{Hsp} 70 / \mathrm{Hsp} 90$ chaperones and the Tom70 receptor to deliver preproteins into mitochondria [45]. Given that Ids2 is a cytoplasmic cochaperone and deletion of IDS2 did not change the mitochondrial ratio of Atp3, we speculate that Ids2 may participate in Atp3's folding before mitochondrial import. Indeed, clients need to be unfolded before mitochondrial import and we cannot exclude the possibility that Ids2 may participate in the unfolding step of Atp3 right before its mitochondrial import. Without the assistance of the Hsc82/Ids2 complex, Atp3 may be subjected to protein degradation.

Atp1 and Atp2 are components of the $F_{1}$ catalytic head, and Atp3 is the $F_{1}$ central stalk [46]. Loss of any subunits may block the assembly of ATP synthase and lead to aggregation of misassembled subunits [47]. Interestingly, interference of Atp3 destabilizes Atp1 and Atp2, and depletion of Atp1 or Atp2 also decreases the protein level of Atp3. Although the complement of Atp3 in ids $2 \Delta$ cells restoring the respiration defect suggests that Atp3 may be a key protein of the complex V, these subunits may affect each other in assembly and stability.

Many evidence showed that the human HSP90 family is directly involved in mitochondria protein quality control and critical in cellular homeostatic [48]. Several studies demonstrated that the chaperone activity of the
HSP90 family is correlated with OXPHOS and OXPHOS-coupled ATP synthesis [49, 50]. Recent researches in TRAP1, a mitochondria-specific HSP90 paralog, using IP-MS analysis, discovered how TRAP1 contributes to regulating OXPHOS and mitochondrial homeostasis [51]. Conversely, there is no mitochondriaspecific HSP90 in yeast and Hsc82 exists in both cytoplasm and mitochondria [52]. By screening yeast Hsc82 interactors, we found that Hsc82-Ids2 is specifically required for $\mathrm{F}_{1}$-ATPase synthase assembly. Since Ids 2 only exists in the cytoplasm, we speculate that Hsc82-Ids2 modulates ATP synthase assembly [53] in the cytoplasm through Atp3.

Ids2 binds Hsc82 and enhances Hsc82's ATPase activity [28]. This scenario is very similar to another cytoplasmic HSP90 cochaperone Aha1 [40]. Under the heat shock condition, Aha1 is highly expressed to help HSP90 to protect their cytoplasmic clients [54]. Here we uncover that Ids2 is upregulated in the glycerol condition. Therefore, we propose that different environmental stresses may stimulate distinct cochaperones to execute their related regulation (Figure S9), and Ids2 cochaperone is specifically activated for protein quality control and mtDNA maintenance during OXPHOS.

\section{Conclusion}

The proton-pumping complexes at the mitochondrial IM produce an electrochemical proton gradient across the membrane that energizes ATP synthase-mediated 
ATP production. But how cells maintain ATP synthase is still elusive. Here we define a proteostasis system of ATP synthase. The Hsc82-Ids2 complex is critical for Atp3's stability. The absence of Hsc82-Ids2 leads to misfolding and degradation of Atp3. And Atp3 or ATP synthase dysfunction can cause proton accumulation in the IMS, which ultimately induces leakage of mtDNA [42, 43]. These findings reveal a mechanism of how a cytoplasmic cochaperone protects a unique client and further safeguards mitochondrial genome integrity.

\section{Methods}

\section{Plasmids and yeast strains}

S. cerevisiae W303 was used as the parental and wildtype strain. Standard genetic and cloning methods were used for all constructions [55]. Deletion mutants and TAP-tagged strains were generated by the double crossover of various selection marker fragments amplified from the Yeast Deletion or TAP-tagged Library (Horizon Discovery) to their wild-type locus. GST-tagged plasmids were obtained from the Yeast GST-tagged ORF Library (Horizon Discovery). The Myc- or HA-tagged strains were created by integrating the $\mathrm{Myc}_{13}$ or $\mathrm{HA}_{3}$ tag inframe downstream of specific genes in the genome. The liquid yeast growth media were rich medium (YEP, 1\% yeast extract, $2 \%$ peptone) or synthetic complete (SC) medium containing either $2 \%$ glucose or $1 \%$ glycerol with $1 \%$ raffinose. Cells were refreshed to the mid-log phase and harvested for the follow-up assays.

For tagged protein expression or phenotype complementation tests, genes were usually inserted into pRS313 or pRS314 [56]. However, genes with low expression levels were inserted into $2 \mu$ plasmid pRS426 or pRS424. For chromosomal mutations, genes were introduced into pRS306. The pRS306 plasmids were linearized by the appropriate restriction enzymes and transformed into the wild-type strain. The pop-out mutants were selected by $0.01 \%$ 5-fluoroorotic acid. All yeast strains, primer sequences, and constructs used in this study are listed in Additional File 4: Table S3.

\section{Flow cytometry analysis of mitochondrial functions}

To analyze the $\Delta \psi_{\mathrm{m}}$, overnight cultured cells in YEP glucose (YEPD) medium were transferred to YEP glycerol (YEPG) for $48 \mathrm{~h}$ and washed with phosphate-buffered saline (PBS). Next, $1 \times 10^{7}$ cells were resuspended in $1 \mathrm{ml}$ YEPG with $175 \mathrm{nM} \mathrm{DiOC}_{6}$. The cell suspension was incubated for $30 \mathrm{~min}$ in the dark and washed with PBS. The stained cells were diluted to $1 \times 10^{6}$ cells $/ \mathrm{ml}$ and analyzed by FACSCalibur using the FL1 channel without compensation.

To analyze the ROS production, cells were cultured in YEPD for $48 \mathrm{~h}$ and washed with PBS. Next, $1 \times 10^{7}$ cells were resuspended in $100 \mu \mathrm{l}$ of PBS, and dihydroethidium
(DHE) (Molecular Probes) was added to a final concentration of $50 \mu \mathrm{M}$. The cell suspension was incubated for $10 \mathrm{~min}$ in the dark and washed with PBS. The stained cells were diluted to $1 \times 10^{6}$ cells $/ \mathrm{ml}$ and analyzed by FACSCalibur using the FL3 channel without compensation.

To analyze the mitochondrial mass, cells were cultured in YEPD or YEPG for $48 \mathrm{~h}$ and stained for $10 \mathrm{~min}$ in $100 \mathrm{nM}$ of nonyl acridine orange (NAO). Stained cells were detected by FACS analysis using the FL1 channel without compensation.

\section{Fluorescence microscopy}

To analyze the $\Delta \psi_{\mathrm{m}}$, cells of indicated strains were cultured in YEPG for $48 \mathrm{~h}$ and visualized directly or after 30 min staining with $175 \mathrm{nM} \mathrm{DiOC}_{6}$. To analyze the ROS production, cells of indicated strains were cultured in YEPD for $48 \mathrm{~h}$ and visualized directly or after $10 \mathrm{~min}$ staining with $50 \mu \mathrm{M}$ DHE. All fluorescence images were captured using an Upright Fluorescence microscope (Zeiss AxioImager. M1). To analyze Ids2 localization, W303 cells containing pRS426-IDS2-GFP and pHS12COX4-DsRed (a mitochondria marker) were grown in SC medium supplemented with $3 \%$ glycerol for $48 \mathrm{~h}$ and visualized directly. Fluorescence images were captured using a confocal microscope (Zeiss LSM880).

\section{Measurement of cellular oxygen consumption and ATP production}

Cellular oxygen consumption rates (OCR) were measured with an XFp Extracellular Flux Analyser and the corresponding Seahorse Wave Desktop Software (Seahorse Bioscience). Yeast cells were refreshed in SC medium supplemented with $2 \%$ glucose and seeded in Seahorse XFp plates coated with Cell-tak (Invitrogen) at $1 \times 10^{6}$ cells per well. Basal OCR was measured for 15 $\min$ at $30{ }^{\circ} \mathrm{C}$. ATP production was calculated by the difference of OCR after 90 min treatment of the ATP synthase inhibitor triethyltin.

\section{Saccharomyces Genome Database and Gene Ontology term analyses}

The Saccharomyces Genome Database (SGD; http:// www.yeastgenome.org/) integrates functional information of budding yeast genes. Potential clients were chosen by the intersection of three pieces of information in SGD: physical interaction proteins of Hsc82, Gene Ontology term mitochondrion, and phenotype of respiratory growth. Essential genes were ruled out in this study because IDS2 deletion is not lethal. Gene Ontology term analyses were conducted with the online resource GO Term Finder supplied in SGD $[57,58]$. 


\section{Quantitative PCR (qPCR)}

To identify mRNA expression level, indicated yeast cells were refreshed in YEPD at 30 or $37^{\circ} \mathrm{C}$ for $3 \mathrm{~h}$ and collected for RNA purification. RNA was extracted using TRIzol reagent (Invitrogen). Complementary DNA (cDNA) was synthesized using SuperScript III Cells Direct cDNA Synthesis Kit (Invitrogen). Quantitative reverse transcription PCR (qRT-PCR) was performed on a BioRad CFX Connect Real-Time PCR Detection System.

Cellular DNA was extracted from the indicated strains to detect mtDNA copy numbers using qPCR. The relative mtDNA copy number was calculated using $\mathrm{qPCR}$ signals from the mtDNA COX1 relative to those from the nuclear DNA ACT1.

\section{Glycerol viability test}

Yeast cells were grown overnight at $30{ }^{\circ} \mathrm{C}$. Overnight cultures were inoculated into fresh YEP or SC glucose medium and grown to exponential phase $\left(\mathrm{OD}_{600}=0.5\right)$. Ten-fold serial dilutions of indicated strains were spotted onto SC plates with $2 \%$ glucose or $3 \%$ glycerol and incubated at $30{ }^{\circ} \mathrm{C}$ for 2 to 3 days.

\section{Co-immunoprecipitation assay}

W303 strains containing C-terminal tagged plasmids (pRS313-ATP1- HA $A_{3}$, pRS313-ATP2-HA,$\quad$ pRS423-ATP3$H A_{3}$, or pRS426-COA3- $H A_{3}$ ) and pRS423-IDS2-Myc $c_{13}$ or pRS426-IDS2- $M y c_{13}$ were grown to OD = 1 in SC medium supplemented with $3 \%$ glycerol. Pellets were resuspended in the lysis buffer $(50 \mathrm{mM} \mathrm{NaCl}, 0.1 \% \mathrm{NP}-40,150 \mathrm{mM}$ Tris- $\mathrm{HCl}, \mathrm{pH}$ 8.0) supplemented with protease inhibitors (Roche). Cells were broken by a FastPrep-24 5G Homogenizer (MP biomedical) and supernatants were collected after centrifugation. The supernatants were mixed with either anti-HA (Roche) or anti-Myc (Roche) antibodies, and followed by incubation with protein G Sepharose beads. Immunoprecipitates were washed four times with the lysis buffer and then eluted by boiling in sample buffer. Samples were resolved by 10\% SDS-PAGE and analyzed by western blotting using the appropriate antibodies.

\section{His-tagged metal affinity purification assay}

pET28a or pGEX4T-1 plasmid was inserted with desired genes and transformed into the BL21 (DE3) tRNA strain. Cells were grown in LB media at $37{ }^{\circ} \mathrm{C}$ overnight, refreshed to $\mathrm{OD}=0.6-0.8$, and induced with $0.1 \mathrm{mM}$ Isopropyl- $\beta$ - $D$-thiogalactoside (IPTG, Sigma-Aldrich) at $16{ }^{\circ} \mathrm{C}$ for $6 \mathrm{~h}$. Cells were collected by centrifugation and lysed with the His-lysis buffer $(300 \mathrm{mM} \mathrm{NaCl}, 50 \mathrm{mM}$ $\mathrm{NaH}_{2} \mathrm{PO}_{4}, 10 \mathrm{mM}$ imidazole, $3 \mathrm{mM} \beta$-mercaptoethanol, $0.5 \%$ NP- $40,10 \%$ glycerol, $\mathrm{pH} 8.0$ ) or the GST-lysis buffer $\left(300 \mathrm{mM} \mathrm{NaCl}, 2.7 \mathrm{mM} \mathrm{KCl}, 10 \mathrm{mM} \mathrm{NaH}_{2} \mathrm{PO}_{4}, 1.8\right.$ $\mathrm{mM} \mathrm{KH_{2 }} \mathrm{PO}_{4}, 3 \mathrm{mM} \beta$-mercaptoethanol) supplemented with $1 \times$ Protease Inhibitor Cocktails (Roche), $1 \mathrm{mM}$
PMSF, and $1 \mathrm{mg} / \mathrm{ml}$ lysozyme (Sigma-Aldrich). After sonication, lysates were centrifuged, and supernatants were incubated with Talon Superflow or Glutathione Sepharose 4B resin (GE HealthCare) for $2 \mathrm{~h}$ at $4{ }^{\circ} \mathrm{C}$. Beads were washed with the His-washing buffer (300 $\mathrm{mM} \mathrm{NaCl}, 50 \mathrm{mM} \mathrm{NaH} \mathrm{PO}_{4}, 20 \mathrm{mM}$ imidazole, $10 \%$ glycerol, pH 8.0) or the GST-washing buffer $(300 \mathrm{mM}$ $\mathrm{NaCl}, 2.7 \mathrm{mM} \mathrm{KCl}, 10 \mathrm{mM} \mathrm{NaH} \mathrm{PO}_{4}, 1.8 \mathrm{mM} \mathrm{KH}_{2} \mathrm{PO}_{4}$ ). For GST-tagged proteins, the beads were eluted by the elution buffer $(50 \mathrm{mM}$ Tris- $\mathrm{HCl}, \mathrm{pH} 8.0,10 \mathrm{mM}$ reduced glutathione) and concentrated by Amicon Ultra- 0.5 centricon (Millipore).

Talon bead-attached His-tagged proteins were incubated with $5 \mu \mathrm{g}$ GST proteins in the incubation buffer (20 mM Tris-HCl, pH 7.4, $100 \mathrm{mM} \mathrm{NaCl}, 0.1 \%$ NP-40) supplemented with $1 \times$ Protease Inhibitor at $4{ }^{\circ} \mathrm{C}$ for $1 \mathrm{~h}$. After washing with the washing buffer $(20 \mathrm{mM}$ Tris$\mathrm{HCl}, \mathrm{pH}$ 7.4, $100 \mathrm{mM} \mathrm{NaCl}, 50 \mathrm{mM}$ imidazole, $0.1 \% \mathrm{NP}-$ 40), sample buffer was added to the beads, and samples were incubated at $95{ }^{\circ} \mathrm{C}$ for 5 min for immunoblotting.

\section{Limited proteolysis}


pRS314- $A T P 3-H A_{3}$ were grown to log phase. All subsequent manipulations were conducted at $4{ }^{\circ} \mathrm{C}$. Cell lysis was performed using glass beads in a native lysis buffer (10 mM Tris- $\mathrm{HCl}, \mathrm{pH} 8.5,50 \mathrm{mM} \mathrm{NaCl}, 15 \mathrm{mM} \mathrm{MgCl}$, and $5 \mathrm{mM}$ DTT). Lysates were incubated with $1 \mathrm{ml}$ preequilibrated anti-HA sepharose beads. After washing, the beads were resuspended in $20 \mu \mathrm{l}$ lysis buffer with $400 \mu \mathrm{g} / \mathrm{ml}$ Proteinase K. Proteolytic digestion was conducted on ice for the indicated period $(0 \sim 40 \mathrm{~min})$. The reaction was stopped by adding $2 \mu \mathrm{l}$ of PMSF $(10 \mathrm{mM})$ and Atp3 fragments were detected by western blotting.

\section{Mitochondria isolation}

W303 pim1 $\Delta$ and ids $2 \Delta$ pim1 1 strains containing pRS414Atp3- $\mathrm{HA}_{3}$ were grown in SC medium supplemented with $1.5 \%$ glycerol and $1.5 \%$ raffinose. Cells were treated with zymolyase and lysed with a Dounce homogenizer, and cellular compartments were isolated by differential centrifugation as described in Yeast Protocol [59].

\section{Abbreviations \\ DHE: Dihydroethidium; DiOC6: 3,3'-Dihexyloxacarbocyanine iodide; ETC: Electron transport chain; HSP: Heat shock protein; IM: Inner membranes; IMS: Intermembrane space; NAO: Nonyl acridine orange; OM: Outer membranes; OXPHOS: Oxidative phosphorylation; ROS: Reactive oxygen species}

\section{Supplementary Information}

The online version contains supplementary material available at https://doi. org/10.1186/s12915-021-01179-x

Additional file 1: Figures S1-S8. Figure S1. HSC82 deleted cells exhibit respiratory defects and comparable expression of Hsp82. Figure 
S2. Nine candidates in the cellular respiration process do not exhibit drastic alteration in protein stability in $h s c 82 \Delta$ and ids $2 \Delta$ cells. Figure $\mathbf{S 3 .}$ mRNA expression levels of the potential clients regulated by the Hsc82Ids2 chaperone complex. Figure S4. Deletion of a potential client can disturb the protein stability of other candidates and HSP90-Ids2-Atp3 forms a ternary complex. Figure S5. Sequence alignments and secondary structure analyses of the Ids2's and Atp3's homologs. Figure S6. The Ids2-Atp3 interaction and the Atp3 stability under various ids2 mutant backgrounds. Figure S7. Respiratory growth, Atp3 levels, Atp3 import, and Atp3 folding in various protease or IDS2 deletional strains. Figure S8. Ids2 plays a dominant role for mitochondria under respiratory growth. Figure S9. A proposed model describes that two Hsc82 cochaperones, Ids2 and Aha1, may split their works under different environmental conditions.

Additional file 2: Table S1. Screen results from SGD database. Additional file 3: Table S2. $G O$ terms analysis of 20 candidate genes. Additional file 4: Table S3. Yeast strains, plasmids, and primer sets used in this study.

Additional file 5. Images of the full immunoblots.

\section{Acknowledgements}

We thank the staff of the Taiwan Yeast Bioresource Center at the First Core Labs, National Taiwan University College of Medicine, for bioresources sharing, and Dr. Fang-Jen Lee for providing pHS12-COX4-DsRed plasmid and porin antibodies. We also thank Drs. Chuang-Rung Chang, Ya-Lan Chang, and Yu-Chen Chen for their critical comments.

\section{Authors' contributions}

P.-H.J. and S.-C.T. conceived and designed the experiments; P.-H.J. and C.-Y.H. performed the experiments; P.-H.J. and S.-C.T. wrote the paper. All authors read and approved the final manuscript.

\section{Funding}

This work was financially supported by the 'Center of Precision Medicine' from The Featured Areas Research Center Program within the framework of the Higher Education Sprout Project by the Ministry of Education and the project of the Ministry of Science and Technology (NTU-110 L901404 \& MOST109-2311-B-002-005-MY3).

\section{Availability of data and materials}

All supporting data in this study are provided in the main article or the associated additional files.

\section{Declarations}

\section{Competing interests}

The authors declare that they have no conflict of interest.

\section{Received: 4 July 2021 Accepted: 28 October 2021}

\section{Published online: 11 November 2021}

\section{References}

1. Lopez-Otin C, Blasco MA, Partridge L, Serrano M, Kroemer G. The hallmarks of aging. Cell. 2013;153(6):1194-217. https://doi.org/10.1016/j.cell.2013.05.03 9.

2. Park CB, Larsson NG. Mitochondrial DNA mutations in disease and aging. J Cell Biol. 2011;193(5):809-18. https://doi.org/10.1083/jcb.201010024.

3. Fernandez-Marcos PJ, Auwerx J. Regulation of PGC-1a, a nodal regulator of mitochondrial biogenesis. Am J Clin Nutr. 2011;93(4):884-s-890.

4. Nakamoto RK, Ketchum CJ, Al-Shawi MK. Rotational coupling in the $\mathrm{F}_{0} \mathrm{~F}_{1}$ ATP synthase. Annu Rev Biophys Biomol Struct. 1999;28(1):205-34. https:// doi.org/10.1146/annurev.biophys.28.1.205

5. Durieux J, Wolff S, Dillin A. The cell-non-autonomous nature of electron transport chain-mediated longevity. Cell. 2011;144(1):79-91. https://doi.org/1 0.1016/j.cell.2010.12.016.

6. Wang K, Klionsky DJ. Mitochondria removal by autophagy. Autophagy. 2011; 7(3):297-300. https://doi.org/10.4161/auto.7.3.14502.
7. Green DR, Galluzzi L, Kroemer G. Mitochondria and the autophagyinflammation-cell death axis in organismal aging. Science. 2011;333(6046): 1109-12. https://doi.org/10.1126/science.1201940.

8. Boyer PD. The ATP synthase--a splendid molecular machine. Annu Rev Biochem. 1997;66(1):717-49. https://doi.org/10.1146/annurev.biochem.66.1. 717.

9. Williamson D. The curious history of yeast mitochondrial DNA. Nat Rev Genet. 2002;3(6):475-81. https://doi.org/10.1038/nrg814.

10. Ling F, Shibata T. Recombination-dependent mtDNA partitioning: in vivo role of Mhr1p to promote pairing of homologous DNA. EMBO J. 2002; 21(17):4730-40. https://doi.org/10.1093/emboj/cdf466.

11. Foury F, Roganti $T$, Lecrenier N, Purnelle B. The complete sequence of the mitochondrial genome of Saccharomyces cerevisiae. FEBS Lett. 1998;440(3): 325-31. https://doi.org/10.1016/50014-5793(98)01467-7.

12. Malina C, Larsson C, Nielsen J. Yeast mitochondria: an overview of mitochondrial biology and the potential of mitochondrial systems biology. FEMS Yeast Res. 2018;18(5). https://doi.org/10.1093/femsyr/foy040.

13. Linnane AW, Marzuki S, Ozawa T, Tanaka M. Mitochondrial DNA mutations as an important contributor to ageing and degenerative diseases. Lancet. 1989;1 (8639):642-5. https://doi.org/10.1016/s0140-6736(89)92145-4.

14. Caron F, Jacq C, Rouvière-Yaniv J. Characterization of a histone-like protein extracted from yeast mitochondria. Proc Natl Acad Sci U S A. 1979;76(9): 4265-9. https://doi.org/10.1073/pnas.76.9.4265.

15. Diffley JF, Stillman B. A close relative of the nuclear, chromosomal highmobility group protein HMG1 in yeast mitochondria. Proc Natl Acad Sci U S A. 1991;88(17):7864-8. https://doi.org/10.1073/pnas.88.17.7864.

16. Kazak $L$, Reyes A, Holt IJ. Minimizing the damage: repair pathways keep mitochondrial DNA intact. Nat Rev Mol Cell Biol. 2012;13(10):659-71. https:// doi.org/10.1038/nrm3439.

17. Quirós PM, Langer T, López-Otín C. New roles for mitochondrial proteases in health, ageing and disease. Nat Rev Mol Cell Biol. 2015;16(6):345-59. https:// doi.org/10.1038/nrm3984.

18. Rowley N, Prip-Buus C, Westermann B, Brown C, Schwarz E, Barrell B, et al. Mdj1p, a novel chaperone of the Dnas family, is involved in mitochondrial biogenesis and protein folding. Cell. 1994;77(2):249-59. https://doi.org/10.1 016/0092-8674(94)90317-4.

19. Ng AC, Baird SD, Screaton RA. Essential role of TID1 in maintaining mitochondrial membrane potential homogeneity and mitochondrial DNA integrity. Mol Cell Biol. 2014;34(8):1427-37. https://doi.org/10.1128/MCB.01 021-13.

20. Lai-Zhang J, Xiao Y, Mueller DM. Epistatic interactions of deletion mutants in the genes encoding the $F_{1}$-ATPase in yeast Saccharomyces cerevisiae. EMBO J. 1999;18(1):58-64. https://doi.org/10.1093/emboj/18.1.58.

21. Trifunovic A, Wredenberg A, Falkenberg M, Spelbrink JN, Rovio AT, Bruder $\mathrm{CE}$, et al. Premature ageing in mice expressing defective mitochondrial DNA polymerase. Nature. 2004;429(6990):417-23. https://doi.org/10.1038/nature02 517.

22. Kujoth GC, Hiona A, Pugh TD, Someya S, Panzer K, Wohlgemuth SE, et al. Mitochondrial DNA mutations, oxidative stress, and apoptosis in mammalian aging. Science. 2005;309(5733):481-4. https://doi.org/10.1126/ science.1112125.

23. Galluzzi L, Kepp O, Kroemer G. Mitochondria: master regulators of danger signalling. Nat Rev Mol Cell Biol. 2012;13(12):780-8. https://doi.org/10.1038/ nrm3479.

24. Genest O, Wickner S, Doyle SM. Hsp90 and Hsp70 chaperones: Collaborators in protein remodeling. J Biol Chem. 2019;294(6):2109-20. https://doi.org/1 0.1074/jbc.REV118.002806.

25. Chiti F, Dobson CM. Protein misfolding, amyloid formation, and human disease: a summary of progress over the last decade. Annu Rev Biochem. 2017;86(1):27-68. https://doi.org/10.1146/annurev-biochem-061516-045115.

26. Li J, Soroka J, Buchner J. The Hsp90 chaperone machinery: conformational dynamics and regulation by co-chaperones. Biochim Biophys Acta. 2012; 1823(3):624-35. https://doi.org/10.1016/j.bbamcr.2011.09.003.

27. Siligardi G, Panaretou B, Meyer P, Singh S, Woolfson DN, Piper PW, et al. Regulation of Hsp90 ATPase activity by the co-chaperone Cdc37p/p50cdc37. J Biol Chem. 2002;277(23):20151-9. https://doi.org/10.1074/jbc.M201287200.

28. Chen YC, Jiang PH, Chen HM, Chen CH, Wang YT, Chen YJ, et al. Glucose intake hampers PKA-regulated HSP90 chaperone activity. Elife. 2018;7. https://doi.org/10.7554/eLife.39925.

29. Petit PX, Glab N, Marie D, Kieffer H, Métézeau P. Discrimination of respiratory dysfunction in yeast mutants by confocal microscopy, image, 
and flow cytometry. Cytometry. 1996;23(1):28-38. https://doi.org/10.1002/ (SICI) 1097-0320(19960101)23:1<28::AID-CYTO5>3.0.CO;2-I.

30. Zielonka J, Vasquez-Vivar J, Kalyanaraman B. Detection of 2-hydroxyethidium in cellular systems: a unique marker product of superoxide and hydroethidine. Nat Protoc. 2008;3(1):8-21. https://doi.org/10.1038/nprot.2 007.473 .

31. Petit JM, Maftah A, Ratinaud MH, Julien R. $10 \mathrm{~N}$-nonyl acridine orange interacts with cardiolipin and allows the quantification of this phospholipid in isolated mitochondria. Eur J Biochem. 1992;209(1):267-73. https://doi. org/10.1111/j.1432-1033.1992.tb17285.x.

32. Goldthwaite CD, Cryer DR, Marmur J. Effect of carbon source on the replication and transmission of yeast mitochondrial genomes. Mol Gen Genet MGG. 1974;133(2):87-104. https://doi.org/10.1007/BF00264830.

33. Zorova LD, Popkov VA, Plotnikov EY, Silachev DN, Pevzner IB, Jankauskas SS, et al. Mitochondrial membrane potential. Anal Biochem. 2018;552:50-9. https://doi.org/10.1016/j.ab.2017.07.009.

34. Yoshida M, Muneyuki E, Hisabori T. ATP synthase - a marvellous rotary engine of the cell. Nat Rev Mol Cell Biol. 2001;2(9):669-77. https://doi.org/1 $0.1038 / 35089509$

35. Kumar TA. CFSSP: Chou and Fasman secondary structure prediction server Wide Spectrum. 2013;1(9):15-9.

36. Ciechanover A. Intracellular protein degradation: from a vague idea thru the lysosome and the ubiquitin-proteasome system and onto human diseases and drug targeting. Cell Death Differ. 2005;12(9):1178-90. https://doi.org/1 $0.1038 / \mathrm{sj} . c d d .4401692$

37. Ammerer G, Hunter CP, Rothman JH, Saari GC, Valls LA, Stevens TH: PEP4 gene of Saccharomyces cerevisiae encodes proteinase A, a vacuolar enzyme required for processing of vacuolar precursors. Mol Cell Biol 1986, 6(7):24902499, DOI: https://doi.org/10.1128/mcb.6.7.2490-2499.1986.

38. Opalinska M, Janska H. AAA Proteases: Guardians of Mitochondrial Function and Homeostasis. Cells. 2018;7(10). https://doi.org/10.3390/cells7100163.

39. Major T, von Janowsky B, Ruppert T, Mogk A, Voos W. Proteomic analysis of mitochondrial protein turnover: identification of novel substrate proteins of the matrix protease Pim1. Mol Cell Biol. 2006;26(3):762-76. https://doi.org/1 0.1128/MCB.26.3.762-776.2006.

40. Lotz GP, Lin H, Harst A, Obermann WM. Aha1 binds to the middle domain of Hsp90, contributes to client protein activation, and stimulates the ATPase activity of the molecular chaperone. J Biol Chem. 2003:278(19):17228-35. https://doi.org/10.1074/jbc.M212761200.

41. Paul MF, Ackerman S, Yue J, Arselin G, Velours J, Tzagolof A, et al. Cloning of the yeast ATP3 gene coding for the gamma-subunit of $F_{1}$ and characterization of atp3 mutants. J Biol Chem. 1994;269(42):26158-64. https://doi.org/10.1016/50021-9258(18)47172-4.

42. Patrushev M, Kasymov V, Patrusheva V, Ushakova T, Gogvadze V, Gaziev A. Mitochondrial permeability transition triggers the release of mtDNA fragments. Cell Mol Life Sci. 2004;61(24):3100-3. https://doi.org/10.1007/ s00018-004-4424-1.

43. Hüser J, Rechenmacher CE, Blatter LA. Imaging the permeability pore transition in single mitochondria. Biophys J. 1998;74(4):2129-37. https://doi. org/10.1016/50006-3495(98)77920-2.

44. Fox TD. Mitochondrial protein synthesis, import, and assembly. Genetics. 2012;192(4):1203-34. https://doi.org/10.1534/genetics.112.141267.

45. Young JC, Hoogenraad NJ, Hartl FU. Molecular chaperones Hsp90 and Hsp70 deliver preproteins to the mitochondrial import receptor Tom70. Cell. 2003;112(1):41-50. https://doi.org/10.1016/S0092-8674(02)01250-3.

46. Walker JE. The ATP synthase: the understood, the uncertain and the unknown. Biochem Soc Trans. 2013;41(1):1-16. https://doi.org/10.1042/BST2 0110773.

47. Song J, Pfanner N, Becker T. Assembling the mitochondrial ATP synthase. Proc Natl Acad Sci U S A. 2018;115(12):2850-2. https://doi.org/10.1073/pna S. 1801697115

48. Altieri DC. Hsp90 regulation of mitochondrial protein folding: from organelle integrity to cellular homeostasis. Cell Mol Life Sci. 2013;70(14): 2463-72. https://doi.org/10.1007/s00018-012-1177-0.

49. Yoshida S, Tsutsumi S, Muhlebach G, Sourbier C, Lee MJ, Lee S, et al. Molecular chaperone TRAP1 regulates a metabolic switch between mitochondrial respiration and aerobic glycolysis. Proc Natl Acad Sci U S A. 2013;110(17):E1604-12. https://doi.org/10.1073/pnas.1220659110.

50. Franco MC, Ricart KC, Gonzalez AS, Dennys CN, Nelson PA, Janes MS, et al. Nitration of Hsp90 on Tyrosine 33 regulates mitochondrial metabolism. J Biol Chem. 2015;290(31):19055-66. https://doi.org/10.1074/jbc.M115.663278.
51. Joshi A, Dai L, Liu Y, Lee J, Ghahhari NM, Segala G, et al. The mitochondrial HSP90 paralog TRAP1 forms an OXPHOS-regulated tetramer and is involved in mitochondrial metabolic homeostasis. BMC Biol. 2020;18(1):10. https://doi. org/10.1186/s12915-020-0740-7.

52. Sickmann A, Reinders J, Wagner Y, Joppich C, Zahedi R, Meyer HE, et al. The proteome of Saccharomyces cerevisiae mitochondria. Proc Natl Acad Sci U S A. 2003;100(23):13207-12. https://doi.org/10.1073/pnas.2135385100.

53. Francis BR, Thorsness PE. Hsp90 and mitochondrial proteases Yme1 and Yta10/12 participate in ATP synthase assembly in Saccharomyces cerevisiae. Mitochondrion. 2011;11(4):587-600. https://doi.org/10.1016/j.mito.2011.03. 008.

54. Panaretou B, Siligardi G, Meyer P, Maloney A, Sullivan JK, Singh S, et al. Activation of the ATPase Activity of Hsp90 by the stress-regulated cochaperone Aha1. Mol Cell. 2002;10(6):1307-18. https://doi.org/10.1016/S1 097-2765(02)00785-2.

55. Ausubel FM. Current protocols in molecular biology; 1987.

56. Sikorski RS, Hieter P. A system of shuttle vectors and yeast host strains designed for efficient manipulation of DNA in Saccharomyces cerevisiae. Genetics. 1989;122(1):19-27. https://doi.org/10.1093/genetics/122.1.19.

57. Cherry JM, Hong EL, Amundsen C, Balakrishnan R, Binkley G, Chan ET, et al. Saccharomyces Genome Database: the genomics resource of budding yeast. Nucleic Acids Res. 2012;40(Database issue):D700-5. https://doi.org/1 0.1093/nar/gkr1029.

58. Cherry JM, Ball C, Weng S, Juvik G, Schmidt R, Adler C, et al. Genetic and physical maps of Saccharomyces cerevisiae. Nature. 1997;387(6632 Suppl):6773. https://doi.org/10.1038/387s067.

59. Meisinger C, Pfanner N, Truscott KN. Isolation of yeast mitochondria. In: Xiao W, editor. Yeast Protocol. Totowa: Humana Press; 2006. p. 33-9.

\section{Publisher's Note}

Springer Nature remains neutral with regard to jurisdictional claims in published maps and institutional affiliations.

\section{Ready to submit your research? Choose BMC and benefit from:}

- fast, convenient online submission

- thorough peer review by experienced researchers in your field

- rapid publication on acceptance

- support for research data, including large and complex data types

- gold Open Access which fosters wider collaboration and increased citations

- maximum visibility for your research: over $100 \mathrm{M}$ website views per year

At BMC, research is always in progress.

Learn more biomedcentral.com/submissions 